\title{
Detecting Outliers in Bioequivalence Studies for Crossover Design
}

\author{
Ghada A. El-Kelany ${ }^{1} \&$ Shimaa M. Ahmed ${ }^{2}$ \\ ${ }^{1,2}$ Department of Statistics, Faculty of Commerce, AL-Azhar University, (Girls' Branch), Cairo, Egypt. \\ Email: gh_elkelany@hotmail.com ${ }^{1} \&$ shimaamohee@yahoo.com²
}

Outliers may affect the conclusion of the decision about the bioequivalence between test drug and reference drug. This paper aims to study the statistical methods to detect outliers in Bioequivalence study for a crossover design. Two methods of detecting outliers are considered, Principal Component Analysis (PCA) and cook's distance. The study is conducting using real data set to achieve the results.

Keywords: Bioequivalence Study, Principal Component Analysis, Cook's Distance.

\section{INTRODUCTION}

Bioequivalence studies are very important for any new treatment (Test drug, $\mathrm{T}$ ) as alternative to the original drug (Reference drug, R). The $\mathrm{T}$ drug must be tested statistically to prove that it is no worse than (or equivalence) to the active control within defined than the original drug, $\mathrm{R}$ drug. Bioequivalence (BE) studies provide a statistical evidence of bioequivalence between two medicinal products ( $T$ drug and $R$ drug) containing the same active substance. A common problem in BE studies is the occurrence of outliers, whether extremely large or small observations. The existing of such observation may affect the conclusion of the decision about the bioequivalence between $\mathrm{T}$ drug and $\mathrm{R}$ drug. The bioequivalence of two formulations of the same drug can be determined based on no significant differences in pharmacokinetic parameters.

The American Food and Drug Administration, FDA (1992), specified the rule that the BE studies must have at least $80 \%$ power of detecting a $10 \%$ difference between the parameters of interest. It was also suggested that $90 \%$ confidence intervals $(\mathrm{CI})$ be used within the pre-specified range $(80 \%, 125 \%)$.

The present study is an extension for the model which presented by Ibrahim (2017). They suggested a model to measure a $\mathrm{BE}$ between formulations using four pharmacokinetic parameter $\boldsymbol{C}_{\boldsymbol{m a x}}, \boldsymbol{T}_{\boldsymbol{m a x}}, \quad \mathbf{A U C}_{\mathbf{0 - t}}, \quad \mathrm{AUC}_{\mathbf{0}-} \infty$, respectively where:

- $\mathbf{C}_{\mathbf{m a x}}$ : Indicates to the maximum drug concentration achieved in systemic circulation following drug administration.

- $\mathbf{T}_{\mathbf{m a x}}$ : the time which required to achieve maximum drug concentration in systemic circulation.

- $\mathbf{A U C}_{0-\mathrm{t}}$ : Area under the plasma concentration-time curve to the last quantifiable concentration to be calculated using trapezoidal rule.

- $\mathbf{A U C}_{0-\infty}$ : Area under the plasma concentration-time curve from 0 to infinity to be calculated as the sum of $\mathbf{A U C} \mathbf{C}_{\text {0-t }}$ plus the ratio of the last measurable concentration to the elimination rate constant. [CDSCO, (2005)]

The real data which used in this study is obtained from Central Administration for Pharmaceutical Affairs (CAPA), in Egypt. The data are divided according to crossover design. A crossover design is a design used when collecting blood samples from study subjects such that pharmacokinetic parameters can be obtained. The present study is 
concerned with detecting outliers in bioequivalent studies for $2 \times 2$ and $3 \times 3$ crossover design. This paper is organized as follows; section 2 is concerned with methods of detecting outliers in bioequivalence. In section 3 , concluding remarks of the results from the data are obtained.

\section{Methods of Detecting Outliers in Bioequivalence:}

There are many methods used to detect outliers in bioequivalence studies. This study is concerned with some of outliers detection methods, These methods are Principal Component Analysis (PCA) and Cook's distance in some details for 2x2 Crossover Design and 3x3 Crossover Design, respectively:

\section{Principal Component Analysis (PCA):}

The objective of PCA is to discover or to reduce the dimensionality of the dataset and identify new meaningful underlying variables. In PCA number of (possibly), correlated variables are transformed into (smaller) number of variables which are uncorrelated called principal components. A large amount of variability is accounted by the first PC and each succeeding PC accounts for as much of the remaining variability as possible. With: $E\left(\sum_{i=1}^{p} \lambda_{i} X^{2}{ }_{1, j}\right)=\sum_{i=1}^{p} \lambda_{i}=p$ And, $\operatorname{Var}\left(\sum_{i=1}^{p} \lambda_{i} X^{2}{ }_{1, j}\right)=2 \sum_{i=1}^{p} \lambda^{2}{ }_{i}$

$\sum_{i=1}^{p} \lambda_{i} X^{2}{ }_{1, j}$ : The weighted sum of square distance to zero of the projected data into principal factorial plane.

$\lambda_{i}$ : is called Eigen value denotes the variance of the $\mathrm{i}^{- \text {th }}$ principal component. For more details, see [Enachescu and Enachescu, (2009)].

Now the Observations with a square distance greater than Threshold $(m)$ may be considered as outliers where $m=p+2 \sqrt{2 \sum_{i=1}^{3} \lambda^{2}}$

\section{For $2 x 2$ Crossover Design:}

In $2 \times 2$ crossover design, subjects' study are randomized into two groups then given a sequence of treatments at uniform intervals of time (periods). In the first sequence, each study subject receives, say, a test treatment in period 1 , then a reference treatment in period 2 and this arrangement is reversed in the second sequence, reference treatment is given followed by the test treatment. [Lim et al (2017)]

In this article, the population study consisted of $(N=24)$ healthy, adult volunteers (subjects), according to real data obtained from Central Administration for Pharmaceutical Affairs (CAPA), in Egypt. The subjects were randomized to receive test and reference drugs in each period in order to eliminate any bias factors.

The study was crossover designed as two-treatment, two-sequence (groups, each group consists of 12 subjects) and two-period (PER I and PERII). Bioequivalence study is made with a washout period. Volunteers must receive the same amount of test and reference drugs. The first group received single oral doses of the test drug (90mg). The second group received three doses of the reference drug $(30 \mathrm{mg})$. Plasma levels of the chemical substance were measured by taking samples of blood from every volunteer during the following times per hour zero: 0.5, 1.0, 1.5, 2.0, 2.5, 3.0, 3.5, 4, 4.5, 5, 5.5, 6, 6.5, 8, 10, 12, 24, 48 and 72. Then after wash out time, in period two, drugs were switched between volunteers as shown below: 


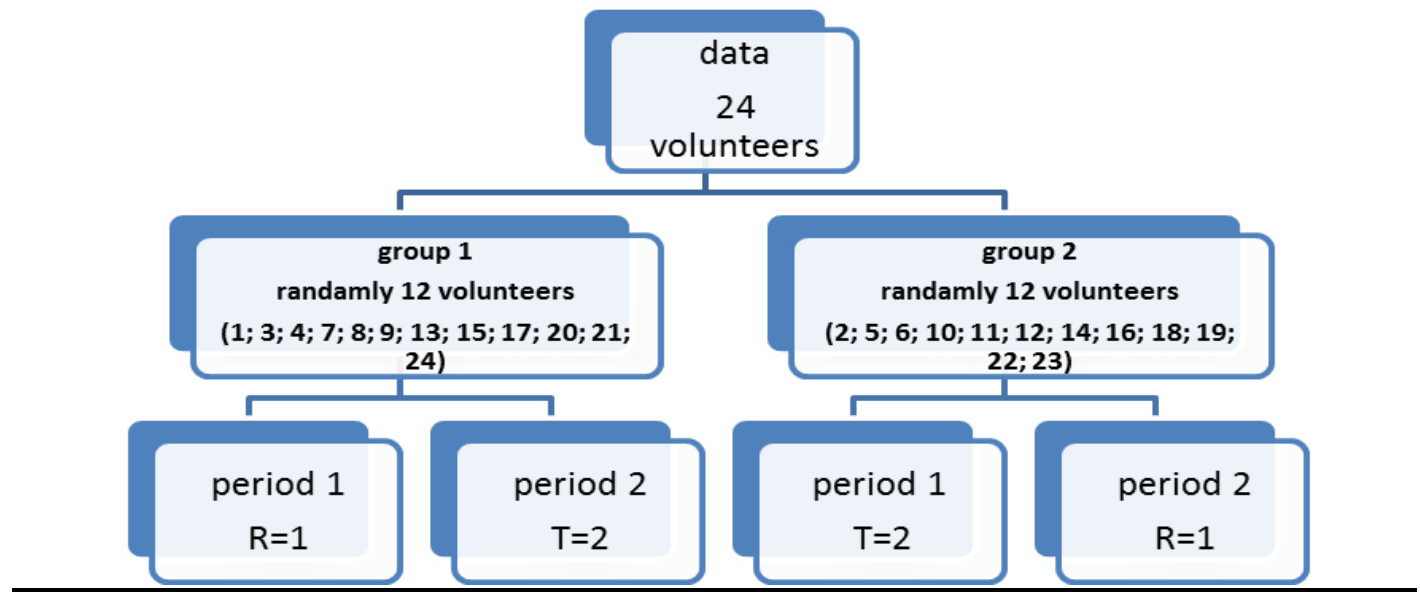

According to $2 \times 2$ Crossover Design, as two-treatment, two-sequence (groups, each group consists of 12 subjects) and two-period (PER I and PERII). The study employed the data described above for both Linear and Logarithmic Scales. SPSS Package is used to apply PCA method to detect outlier observations. The results are obtained from table (1-a) to table (4-b) for each parameter, $\boldsymbol{C}_{\max }, \boldsymbol{T}_{\max }, \boldsymbol{A} \boldsymbol{U} \boldsymbol{C}_{(\mathbf{0}-\mathrm{t})}$ and $\boldsymbol{A} \boldsymbol{U} \boldsymbol{C}_{\left(\mathbf{0}-\infty_{)}\right.}$, respectively, reported in Appendix (A).

According to table (1-b), by comparing between Squared distance and Threshold (6.808) for linear scale and (6.8849) for Logarithmic Scale, it was found that, there are no outliers for the $\boldsymbol{C}_{\boldsymbol{m a x}}$ parameter.

According to table (2-b), by comparing between Squared distance and Threshold (6.054) for linear scale and (6.08) for Logarithmic Scale, it was found that, there are two outlier observations for the $\boldsymbol{T}_{\max }$ parameter, $1^{\text {st }}$ and $7^{\text {th }}$ subject respectively.

According to table (3-b), by comparing between Squared distance and Threshold (6.813) for linear scale and (6.75338) for Logarithmic Scale, it was found that, there are two outlier observations for the $\boldsymbol{A} \boldsymbol{U} \boldsymbol{C}_{\boldsymbol{0}-\mathrm{t}}$ parameter, $10^{\text {th }}$ and $18^{\text {th }}$ subject respectively. According to table (4-b), by comparing between Squared distance and Threshold (6.076) for linear scale and (6.43) for Logarithmic Scale, it was found that, there are two outlier observations for the $\boldsymbol{A} \boldsymbol{U} \boldsymbol{C}_{\left(0_{-} \infty\right)} \infty$ parameter, $10^{\text {th }}$ and $15^{\text {th }}$ subject respectively.

\section{For 3x3 Crossover Design:}

In this section, the PCA techniques for detecting outliers for $3 \times 3$ Crossover Design is illustrated. For more details, see Kirtiraj (2014). The study used a new data contains of:

- Three drugs : two test (T1 and T2) and Reference (R) drugs.

- 12 healthy volunteers (subjects). Volunteers must receive the same amount of drugs.

- According to $3 \times 3$ crossover design, the data is divided into three groups (sequence) randomized. Each group consists of randomly 4 volunteers.

- Each group is divided into three periods and between the each periods a period of rest of the each treatment. Then after wash out time, drugs were switched between volunteers as shown below: 


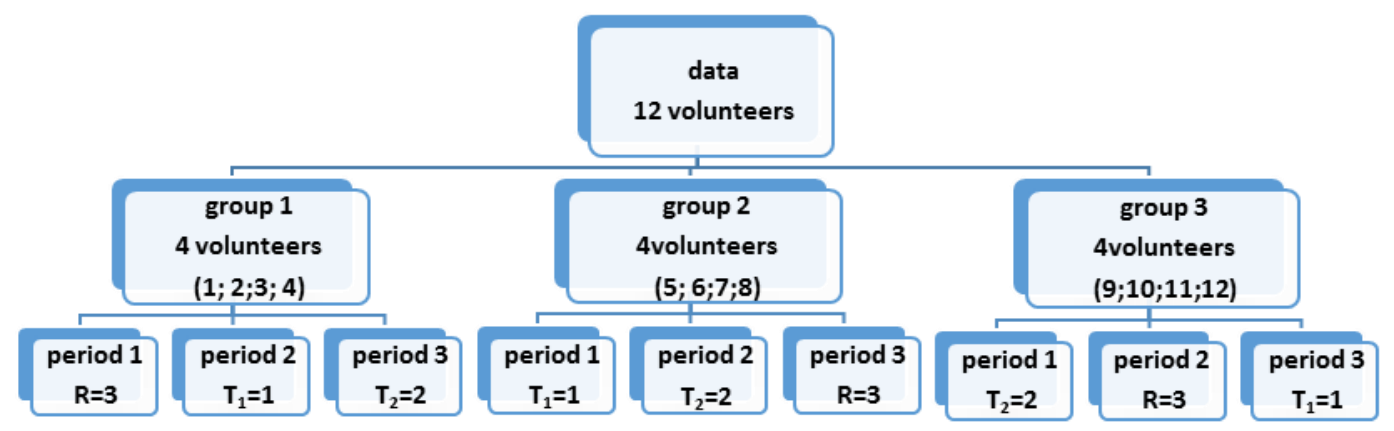

SPSS Package is used to detect outliers by PCA method for both Linear and Logarithmic scales. The results are

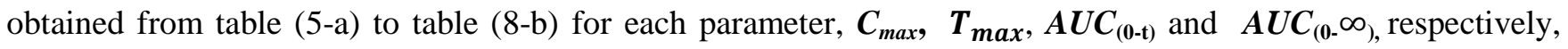
reported in Appendix (A).

According to table (5-b), by comparing between Squared distance and Threshold (8.44165) for Logarithmic Scale, there is no outlier was found. Table (5-b) shows that there is one outlier observation for the $\boldsymbol{C}_{\max }$ parameter which is $7^{\text {th }}$ subject.

According to table (6-b), by comparing between Squared distance and Threshold (8.32619) for linear scale, it was found that, there is no outlier observation for the $\boldsymbol{T}_{\boldsymbol{m a x}}$ parameter. Also, for Threshold (8.37496) for Logarithmic Scale, there is no outlier was found.

According to table (7-b), by comparing between Squared distance and Threshold (10.0015) for linear scale, it was found that, there is no outlier observation for the $A U C_{0-t}$ parameter. Also, for Threshold (10.37676) for Logarithmic Scale, there is no outlier was found.

According to table (8-b), by comparing between Squared distance and Threshold (10.244339) for linear scale, it was found that, there is no outlier observations for the $\boldsymbol{A} \boldsymbol{U} \boldsymbol{C}_{(0-\infty)}$, parameter. Also, for Threshold (10.5203) for Logarithmic Scale, there is no outlier was found.

\section{Cook's Distance:}

Cook's distance technique $\left(\boldsymbol{D}_{\boldsymbol{i}}\right)$ is applied to detect outlier observations. It is useful for identifying outliers. Observations are outliers if $\boldsymbol{D}_{\boldsymbol{i}}$ is larger than three times the mean. $\boldsymbol{D}_{\boldsymbol{i}}$ is a combination of each observation's leverage and residual values; the higher the leverage and residuals, the higher the Cook's distance The formula for Cook's distance is.

$$
D_{i}=\frac{\sum_{j=1}^{n}\left(\widehat{Y}_{j}-\widehat{Y}_{j(i)}\right)^{2}}{(p+\mathbf{1}) \widehat{\sigma}^{2}}
$$

Where:

- $\hat{y}_{j}:$ The $j^{\text {th }}$ fitted response value.

- $\hat{y}_{j(i)}$ : The $j^{\text {th }}$ fitted response value, where the fit does not include observation $i$. 
- $p$ : the number of coefficients in the regression model.

- A general rule of thumb is that observations with a Cook's D of more than 3 times the mean, $\mu$, is a possible outlier.

- An alternative interpretation is to investigate any point over $4 / n$, where $n$ is the number of observations.

[Cook (1977)]

\section{Cook's Distance for $2 \times 2$ Crossover Design:}

The study employed the same data described in PCA method in subsection (2-1-2). In $2 \times 2$ crossover design, the number of observation were 48, where for each person he took both of two drugs, $\mathrm{T}$ and $\mathrm{R}$ drugs. SPSS Package is used to detect outliers by Cook's distance. The results are obtained in table 9, reported in Appendix (A).

Table 9 shows that there are outliers of pharmacological parameters but some of them affect and some are ineffective.

For parameter $\boldsymbol{C}_{\max }$, there are values greater than three times the mean, but the difference between them is not large. It is assumed that they do not affect the results.

For parameter $\boldsymbol{T}_{\boldsymbol{m a x}}$, there are values greater than three times the mean but there are values the difference between them is not large. It is assumed that they do not affect the results. There is one value difference large between them and three times the average can be said to be outliers, this is $8^{\text {th }}$ subject.

For parameter $\boldsymbol{A} \boldsymbol{U} \boldsymbol{C}_{0-t}$, there are some values greater than three times the mean but there are values the difference between them is not large it is assumed they do not affect the results. There is one value difference large between them and three times the average can be said to be outliers is $18^{\text {th }}$ subject.

For parameter $\boldsymbol{A} \boldsymbol{U} \boldsymbol{C}_{\left(0_{-}-\infty\right)}$, there are some values greater than three times the mean but there are values the difference between them is not large it is assumed they do not affect the results. There are two values difference large between them and three times the average can be said to be outliers are $10^{\text {th }}$ and $15^{\text {th }}$ subject.

Figures, from 1 to 4, reported in Appendix (B), show the results graphically, using SPSS Package, according to Cook's distance for $2 \times 2$ crossover design.

\section{Cook's Distance for 3x3 Crossover Design:}

The study employed the same data described in PCA method in subsection (2-1-2). In $3 \times 3$ crossover design, the number of observation were 36, where for each person he took three drugs, T1 and T2 and R drugs. SPSS Package is used to detect outliers for Cook's distance. The results are obtained in table 10, reported in Appendix (A).

Table 10 shows that there are outliers of pharmacological parameters but some of them affect and some are ineffective.

For parameter $\boldsymbol{C}_{\max }$, there are some values greater than three times the mean, but the difference between them is not large. It is assumed that they do not affect the results. For parameter $\boldsymbol{T}_{\max }$, there are some values greater than three times the mean but the difference between them is not large, it is assumed that they do not affect the results. There is one value difference large between them and three times the average can be said to be outliers is $12^{\text {th }}$ subject. 
For parameter $\boldsymbol{A} \boldsymbol{U} \boldsymbol{C}_{\boldsymbol{0}-\boldsymbol{t}}$, there are values greater than three times the mean, but the difference between them is not large. It is assumed that they do not affect the results. There is one value difference large between them and three times the average can be said to be outliers is $10^{\text {th }}$ subject.

For parameter $\boldsymbol{A} \boldsymbol{U} \boldsymbol{C}_{(0-\infty)} \infty$ there are values greater than three times the mean but there are values the difference between them is not large it is assumed they do not affect the results. There is one value difference large between them and three times the average can be said to be outliers is $5^{\text {th }}$ subject.

Figures, from 5 to 8, reported in Appendix (B), show the results graphically, using SPSS package, according to cook's distance for $3 \times 3$ crossover design

\section{CONCLUDING REMARKS}

According to the present study, Test drugs should be as safe and effective as reference drugs to guarantee safety and effectiveness of test drugs. In practice, if test drugs never have the treatment formulations and exactly the same bioavailability of test drugs, an insignificant difference would be always exist between them. Based on the results obtained for bioequivalence in the presence of outliers in this study, it can be indicated that, although the presences of some outliers in the datasets, but the most of these outliers could not had too much effect on the results. But if these outliers have a clear presence in the datasets, in this case, these values should be removed. On the other hand, if these outliers cannot be removed, may be the investigator, for example, could replace these outlier values with the mean of the remaining data to avoid undesirable effect or bad effect of these values.

\section{REFERENCES}

- Cook, R. D., (1977). "Detection of influential observation in linear regression. Technometrics", 15-18,

- Chow S. C. and Tse S. K. (1990) " Outlier detection in bioavailability/bioequivalence studies ". Stat Med, 9(5):549-58.

- CDSCO (2005) Guidelines for Bioavailability and Bioequivalence studies, Central Drugs Standard Control Organization, Directorate General of Health Services, Ministry of Health and Family Welfare, Government of India, New Delhi, pp. 1-34.

Enachescu D. and Enachescu C. (2009) "A new approach for outlying records in bioequivalence trials". Paper presented at The 13th International Conference on Applied Stochastic Models and Data Analysis. Vilnius, Lithuania; 250-257.

- FDA (1992) Guidance on Statistical Procedures for Bioequivalence Using a Standard Two-Treatment Crossover Design US Department of Health and Human Services Food and Drug Administration, Center for

Drug Evaluation and Research (CDER), Rockville, Maryland, pp. 1 -12.

- Ibrahim, I. H., Kalil, F. A., El-Kelany. G. A. and Ahmed. S. M. (2017) "Anova And Manova Analysis in Bio equivalence Study". JP Journal of Biostatistics 14 (1). pp 61-74 
LIM F. P., Mohamed I., Noorizam D. and Goh S. L. (2016) "Comparison of Outlier Detection Methods in Standard 2×2 Crossover Design". Sains Malaysiana 45(3) (2016): 499-506.

- Kirtiraj. M., (2014). "Sapling Size Calculation for Three-Treatment Three-Period Cross-Over Design with Normal Response". A Published Thesis Presented to the Faculty of San Diego State University in Partial Fulfillment of the Requirements for the Degree Master of Science in Statistics.

\section{APPENDIX (A)}

PCA for 2x2 Crossover Design

For $C_{\text {max }}$ parameter

Table (1-a): Eigen-Values for the Linear and Logarithmic Scales to $C_{\max }$

\begin{tabular}{|c|c|c|c|c|c|c|c|c|}
\hline & \multicolumn{3}{|c|}{ Linear Scale } & $m$ & \multicolumn{3}{|c|}{ Logarithmic Scale } & $m$ \\
\hline & $\begin{array}{l}\text { Eigen } \\
\text { values }\end{array}$ & Proportion & Cumulative & & $\begin{array}{l}\text { Eigen } \\
\text { values }\end{array}$ & Proportion & Cumulative & \\
\hline 1 & 1.6670 & 0.834 & 0.834 & 0.000 & 1.7010 & 0.850 & 0.850 & 0.0049 \\
\hline 2 & 0.3330 & 0.166 & 1 & & 0.2990 & 0.150 & 1 & \\
\hline
\end{tabular}

Table (1-b): Threshold Value and the Squared Distance on Linear and Logarithmic Scales to $C_{\max }$ :

\begin{tabular}{|c|c|c|c|c|}
\hline \multirow{2}{*}{ Subjects } & \multicolumn{2}{|c|}{ Linear scale } & \multicolumn{2}{c|}{ Logarithmic Scale } \\
\cline { 2 - 5 } & $\begin{array}{l}\text { Squared } \\
\text { distance }\end{array}$ & $\boldsymbol{m}$ & $\begin{array}{l}\text { Squared } \\
\text { distance }\end{array}$ & $\boldsymbol{m}$ \\
\hline $\mathbf{1}$ & 0.292205 & $\mathbf{6 . 8 0 8}$ & 0.117841 & $\mathbf{6 . 8 8 4 9}$ \\
\hline $\mathbf{2}$ & 0.816273 & & 0.536746 & \\
\hline $\mathbf{3}$ & 0.659577 & & 0.680656 & \\
\hline $\mathbf{4}$ & 0.056346 & & 0.006443 & \\
\hline $\mathbf{5}$ & 1.320921 & & 1.28478 & \\
\hline $\mathbf{6}$ & 5.058621 & & 3.279357 & \\
\hline $\mathbf{7}$ & 2.642502 & & 2.373858 & \\
\hline $\mathbf{8}$ & 4.009222 & & 2.922897 & \\
\hline $\mathbf{9}$ & 0.442939 & & 0.245346 & \\
\hline $\mathbf{1 0}$ & 5.230638 & & 3.756424 & \\
\hline
\end{tabular}




\begin{tabular}{|l|l|l|l|l|}
\hline $\mathbf{1 1}$ & 0.400073 & & 0.220627 & \\
\hline $\mathbf{1 2}$ & 2.520026 & & 3.275803 & \\
\hline $\mathbf{1 3}$ & 3.653834 & & 6.272092 & \\
\hline $\mathbf{1 4}$ & 0.044758 & & 0.137969 & \\
\hline $\mathbf{1 5}$ & 1.853063 & & 1.925527 & \\
\hline $\mathbf{1 6}$ & 0.934129 & & 1.195209 & \\
\hline $\mathbf{1 7}$ & 1.760393 & & 1.851076 & \\
\hline $\mathbf{1 8}$ & 2.631723 & & 3.411712 & \\
\hline $\mathbf{1 9}$ & 0.231058 & & 0.065552 & \\
\hline $\mathbf{2 0}$ & 3.628451 & & 3.051832 & \\
\hline $\mathbf{2 1}$ & 1.206296 & & 1.430743 & \\
\hline $\mathbf{2 2}$ & 2.641721 & & 4.291098 & \\
\hline $\mathbf{2 3}$ & 1.341158 & & 1.792048 & \\
\hline $\mathbf{2 4}$ & 2.624074 & & 1.874367 & \\
\hline & & & & \\
\hline
\end{tabular}

For $T_{\max }$ parameter

Table (2-a): Eigen-Values for the Linear and Logarithmic Scales to $T_{\max }$

\begin{tabular}{|c|c|c|c|c|c|c|c|c|}
\hline & \multicolumn{3}{|c|}{ Linear Scale } & $M$ & \multicolumn{3}{|c|}{ Logarithmic Scale } & $m$ \\
\hline & $\begin{array}{l}\text { Eigen } \\
\text { values }\end{array}$ & Proportion & Cumulative & & $\begin{array}{l}\text { Eigen } \\
\text { values }\end{array}$ & Proportion & Cumulative & \\
\hline 1 & 1.1651 & 0.583 & 0.583 & 0.034 & 1.2013 & 0.601 & 0.601 & 0.0000 \\
\hline 2 & 0.8349 & 0.417 & 1 & & 0.7987 & 0.399 & 1 & \\
\hline
\end{tabular}

Table (2-b): Threshold Value and the Squared Distance on Linear and Logarithmic Scales to $T_{\max }$

\begin{tabular}{|c|c|c|c|c|}
\hline \multirow{2}{*}{ Subjects } & \multicolumn{2}{|c|}{ Linear scale } & \multicolumn{2}{c|}{ Logarithmic Scale } \\
\cline { 2 - 5 } & $\begin{array}{l}\text { Squared } \\
\text { distance }\end{array}$ & $\boldsymbol{m}$ & $\begin{array}{l}\text { Squared } \\
\text { distance }\end{array}$ & $\boldsymbol{M}$ \\
\hline $\mathbf{1}$ & 6.347855 & $\mathbf{6 . 0 5 4}$ & 4.388171 & $\mathbf{6 . 0 8 0 0}$ \\
\hline $\mathbf{2}$ & 2.297066 & & 4.048853 & \\
\hline
\end{tabular}


(Quarterly International Journal) Volume 4, Issue 1, Pages 30-49, January-March 2020

\begin{tabular}{|c|c|c|}
\hline 3 & 0.502297 & 0.568065 \\
\hline 4 & 0.565021 & 0.301535 \\
\hline 5 & 4.372961 & 2.527352 \\
\hline 6 & 1.764949 & 1.74148 \\
\hline 7 & 4.038462 & 6.820777 \\
\hline 8 & 2.45064 & 5.266462 \\
\hline 9 & 1.607051 & 1.54805 \\
\hline 10 & 1.367655 & 1.802514 \\
\hline 11 & 0.338866 & 0.247664 \\
\hline 12 & 0.026936 & 0.176717 \\
\hline 13 & 0.072167 & 0.046449 \\
\hline 14 & 1.913013 & 2.208554 \\
\hline 15 & 3.121881 & 2.724687 \\
\hline 16 & 0.93796 & 1.01109 \\
\hline 17 & 0.598727 & 0.558705 \\
\hline 18 & 0.415242 & 0.509174 \\
\hline 19 & 0.140014 & 0.337831 \\
\hline 20 & 0.406713 & 0.221234 \\
\hline 21 & 5.089844 & 3.297713 \\
\hline 22 & 5.669389 & 3.877557 \\
\hline 23 & 1.616426 & 1.521704 \\
\hline 24 & 0.338866 & 0.247664 \\
\hline
\end{tabular}

For $\left.A U C_{(0-t)}\right)$ parameter

Table (3-a): Eigen-Values for the Linear and Logarithmic Scales to $\mathrm{AUC}_{(0-\mathrm{t})}$

\begin{tabular}{|c|c|c|c|c|c|c|c|}
\hline \multicolumn{3}{|c|}{ Linear Scale } & $m$ & \multicolumn{3}{c|}{ Logarithmic Scale } & $m$ \\
\hline $\begin{array}{c}\text { Eigen } \\
\text { values }\end{array}$ & Proportion & Cumulative & 6.6813 & $\begin{array}{c}\text { Eigen } \\
\text { values }\end{array}$ & Proportion & Cumulative & 6.75338 \\
\hline
\end{tabular}




\begin{tabular}{|c|c|c|c|c|c|c|}
\hline $\mathbf{1}$ & 1.6079 & 0.804 & 0.804 & 1.6416 & 0.821 & 0.821 \\
\hline 2 & 0.3921 & 0.196 & 1 & 0.3584 & 0.179 & 1 \\
\hline
\end{tabular}

Table (3-b): Threshold Value and the Squared Distance on Linear and Logarithmic Scales to AUC $\mathrm{AU}_{(0-\mathrm{t})}$

\begin{tabular}{|c|c|c|c|c|}
\hline \multirow{2}{*}{ Subjects } & \multicolumn{2}{|c|}{ Linear scale } & \multicolumn{2}{c|}{ Logarithmic Scale } \\
\cline { 2 - 5 } & $\begin{array}{l}\text { Squared } \\
\text { distance }\end{array}$ & $\boldsymbol{m}$ & $\begin{array}{l}\text { Squared } \\
\text { distance }\end{array}$ & $\mathbf{M}$ \\
\hline $\mathbf{1}$ & 1.130739 & $\mathbf{6 . 6 8 1 3}$ & 1.166421 & $\mathbf{6 . 7 5 3 3 8}$ \\
\hline $\mathbf{2}$ & 0.130936 & & 0.189553 & \\
\hline $\mathbf{3}$ & 2.693126 & & 1.787536 & \\
\hline $\mathbf{4}$ & 0.828198 & & 0.760176 & \\
\hline $\mathbf{5}$ & 3.640664 & & 3.004641 & \\
\hline $\mathbf{6}$ & 1.315992 & & 1.266076 & \\
\hline $\mathbf{7}$ & 4.824435 & & 3.587424 & \\
\hline $\mathbf{8}$ & 1.672631 & & 1.750794 & \\
\hline $\mathbf{9}$ & 1.064299 & & 0.92472 & \\
\hline $\mathbf{1 0}$ & 9.755956 & & 5.838646 & \\
\hline $\mathbf{1 1}$ & 0.089366 & & 0.288052 & \\
\hline $\mathbf{1 2}$ & 0.211984 & & 0.196616 & \\
\hline $\mathbf{1 3}$ & 1.206321 & & 0.967642 & \\
\hline $\mathbf{1 4}$ & 0.048347 & & 0.010055 & \\
\hline $\mathbf{1 5}$ & 0.293516 & & 0.448449 & \\
\hline $\mathbf{1 6}$ & 0.033572 & & 0.05923 & \\
\hline $\mathbf{1 7}$ & 3.119882 & & 4.216528 & \\
\hline & & & & \\
\hline
\end{tabular}


(Quarterly International Journal) Volume 4, Issue 1, Pages 30-49, January-March 2020

\begin{tabular}{|l|l|l|l|l|}
\hline $\mathbf{2 2}$ & 2.437192 & & 3.63084 & \\
\hline $\mathbf{2 3}$ & 0.840124 & & 0.820937 & \\
\hline $\mathbf{2 4}$ & 0.365857 & & 0.289085 & \\
\hline
\end{tabular}

For $A U C_{\left(0_{-} \infty\right)}$ parameter

Table (4-a): Eigen-Values for the Linear and Logarithmic Scales to $\mathrm{AUC}_{(0-\infty)}$

\begin{tabular}{|c|c|c|c|c|c|c|c|c|}
\hline & \multicolumn{3}{|c|}{ Linear Scale } & $m$ & \multicolumn{3}{|c|}{ Logarithmic Scale } & $m$ \\
\hline & $\begin{array}{l}\text { Eigen } \\
\text { values }\end{array}$ & $\begin{array}{c}\text { Proportio } \\
\text { n }\end{array}$ & $\begin{array}{c}\text { Cumulati } \\
\text { ve }\end{array}$ & \multirow{3}{*}{6.076} & $\begin{array}{l}\text { Eigen } \\
\text { values }\end{array}$ & $\begin{array}{c}\text { Proportio } \\
\text { n }\end{array}$ & $\begin{array}{c}\text { Cumulati } \\
\text { ve }\end{array}$ & \multirow{3}{*}{6.43} \\
\hline 1 & 1.1957 & 0.598 & 0.598 & & 1.4762 & 0.738 & 0.738 & \\
\hline 2 & 0.8043 & 0.402 & 1 & & 0.5238 & 0.262 & 1 & \\
\hline
\end{tabular}

Table (4-b): Threshold Value and the Squared Distance on Linear and Logarithmic Scales to $\mathrm{AUC}_{(0-} \infty$ )

\begin{tabular}{|c|c|c|c|c|}
\hline \multirow{2}{*}{ Subjects } & \multicolumn{2}{|l|}{ Linear scale } & \multicolumn{2}{l|}{ Logarithmic Scale } \\
\cline { 2 - 5 } & $\begin{array}{l}\text { Squared } \\
\text { distance }\end{array}$ & $\boldsymbol{m}$ & $\begin{array}{l}\text { Squared } \\
\text { distance }\end{array}$ & $\boldsymbol{m}$ \\
\hline $\mathbf{1}$ & 3.925195 & $\mathbf{6 . 0 7 6}$ & 3.364347 & $\mathbf{6 . 4 3}$ \\
\hline $\mathbf{2}$ & 0.186792 & & 0.110908 & \\
\hline $\mathbf{3}$ & 0.363777 & & 0.611628 & \\
\hline $\mathbf{4}$ & 0.229681 & & 0.327462 & \\
\hline $\mathbf{5}$ & 0.608863 & & 1.302561 & \\
\hline $\mathbf{6}$ & 0.499782 & & 0.738279 & \\
\hline $\mathbf{7}$ & 0.57144 & & 1.399878 & \\
\hline $\mathbf{8}$ & 0.304627 & & 0.987484 & \\
\hline $\mathbf{9}$ & 0.564519 & & 1.061837 & \\
\hline $\mathbf{1 0}$ & 12.32783 & & 6.938618 & \\
\hline $\mathbf{1 1}$ & 0.037797 & & 0.100451 & \\
\hline $\mathbf{1 2}$ & 0.196569 & & 0.355952 & \\
\hline
\end{tabular}




\begin{tabular}{|l|l|l|l|l|}
\hline $\mathbf{1 3}$ & 0.795239 & & 1.169819 & \\
\hline $\mathbf{1 4}$ & 0.148041 & & 0.107392 & \\
\hline $\mathbf{1 5}$ & 17.31843 & & 9.200627 & \\
\hline $\mathbf{1 6}$ & 0.295323 & & 0.494621 & \\
\hline $\mathbf{1 7}$ & 1.973091 & & 5.71573 & \\
\hline $\mathbf{1 8}$ & 1.959896 & & 5.500872 & \\
\hline $\mathbf{1 9}$ & 0.528605 & & 0.577337 & \\
\hline $\mathbf{2 0}$ & 0.397433 & & 0.571075 & \\
\hline $\mathbf{2 1}$ & 1.497086 & & 3.369482 & \\
\hline $\mathbf{2 2}$ & 0.236245 & & 0.192456 & \\
\hline $\mathbf{2 3}$ & 0.485104 & & 1.212364 & \\
\hline $\mathbf{2 4}$ & 0.548629 & & 0.588821 & \\
\hline
\end{tabular}

PCA for 3x3 Crossover Design

For $C_{\text {max }}$ parameter

Table (5-a): Eigen-Values for the Linear and Logarithmic Scales for $\mathrm{C}_{\max }$

\begin{tabular}{|c|c|c|c|c|c|c|c|c|}
\hline & \multicolumn{3}{|c|}{ Linear Scale } & $m$ & \multicolumn{3}{|c|}{ Logarithmic Scale } & $m$ \\
\hline & $\begin{array}{l}\text { Eigen } \\
\text { values }\end{array}$ & Proportion & Cumulative & & $\begin{array}{l}\text { Eigen } \\
\text { values }\end{array}$ & Proportion & Cumulative & \\
\hline $\mathbf{1}$ & 1.4902 & 0.497 & 0.497 & 8.22097 & 1.6489 & 0.550 & 0.550 & 8.44165 \\
\hline 2 & 0.9080 & 0.303 & 0.799 & & 0.8623 & 0.287 & 0.837 & \\
\hline 3 & 0.6018 & 0.201 & 1.000 & & 0.4889 & 0.163 & 1.000 & \\
\hline
\end{tabular}

Table (5-b): Threshold Value and the Squared Distance on Linear and Logarithmic Scales

\begin{tabular}{|l|c|c|c|c|}
\hline \multirow{2}{*}{ subjects } & \multicolumn{2}{|c|}{ Linear scale } & \multicolumn{2}{c|}{ Logarithmic Scale } \\
\cline { 2 - 5 } & $\begin{array}{l}\text { Squared } \\
\text { distance }\end{array}$ & $\boldsymbol{m}$ & $\begin{array}{l}\text { Squared } \\
\text { distance }\end{array}$ & $\boldsymbol{M}$ \\
\hline $\mathbf{1}$ & 0.222558 & $\mathbf{8 . 2 2 0 9 7}$ & 0.204182 & $\mathbf{8 . 4 4 1 6 5}$ \\
\hline $\mathbf{2}$ & 5.830684 & & 6.384072 & \\
\hline
\end{tabular}




\begin{tabular}{|l|l|l|l|l|}
\hline $\mathbf{3}$ & 1.47235 & & 1.533581 & \\
\hline $\mathbf{4}$ & 3.263167 & & 2.713873 & \\
\hline $\mathbf{5}$ & 1.351464 & & 1.209467 & \\
\hline $\mathbf{6}$ & 2.175122 & & 1.797298 & \\
\hline $\mathbf{7}$ & 7.082718 & & 8.907234 & \\
\hline $\mathbf{8}$ & 1.389955 & & 1.250126 & \\
\hline $\mathbf{9}$ & 1.352193 & & 1.163977 & \\
\hline $\mathbf{1 0}$ & 3.917405 & & 3.274342 & \\
\hline $\mathbf{1 1}$ & 3.031144 & & 2.88769 & \\
\hline $\mathbf{1 2}$ & 1.91124 & & 1.674158 & \\
\hline
\end{tabular}

For $T_{\max }$ parameter

Table (6-a): Eigen-Values for the Linear and Logarithmic Scales for $T_{\max }$

\begin{tabular}{|c|c|c|c|c|c|c|c|c|}
\hline & \multicolumn{3}{|c|}{ Linear Scale } & $m$ & \multicolumn{3}{|c|}{ Logarithmic Scale } & $m$ \\
\hline & $\begin{array}{l}\text { Eigen } \\
\text { values }\end{array}$ & Proportion & Cumulative & & $\begin{array}{l}\text { Eigen } \\
\text { values }\end{array}$ & Proportion & Cumulative & \\
\hline 1 & 1.5021 & 0.501 & 0.501 & 8.32619 & 1.5610 & 0.520 & 0.520 & 8.37496 \\
\hline 2 & 1.0386 & 0.346 & 0.847 & & 0.9834 & 0.328 & 0.848 & \\
\hline 3 & 0.4594 & 0.153 & 1 & & 0.4555 & 0.152 & 1 & \\
\hline
\end{tabular}

Table (6-b): Threshold Value and the Squared Distance on Linear and Logarithmic Scales

\begin{tabular}{|c|c|c|c|c|}
\hline \multirow{2}{*}{ Subjects } & \multicolumn{2}{|c|}{ Linear scale } & \multicolumn{2}{c|}{ Logarithmic Scale } \\
\cline { 2 - 5 } & $\begin{array}{l}\text { Squared } \\
\text { distance }\end{array}$ & $\boldsymbol{m}$ & $\begin{array}{l}\text { Squared } \\
\text { distance }\end{array}$ & $\boldsymbol{M}$ \\
\hline $\mathbf{1}$ & 0.853127 & $\mathbf{8 . 3 2 6 1 9}$ & 0.785971 & $\mathbf{8 . 3 7 4 9 6}$ \\
\hline $\mathbf{2}$ & 4.358666 & & 4.766511 & \\
\hline $\mathbf{3}$ & 3.932859 & & 3.767538 & \\
\hline $\mathbf{4}$ & 0.711192 & & 0.633187 & \\
\hline $\mathbf{5}$ & 2.173905 & & 2.813442 & \\
\hline
\end{tabular}




\begin{tabular}{|l|c|l|l|l|}
\hline $\mathbf{6}$ & 2.698289 & & 2.757822 & \\
\hline $\mathbf{7}$ & 3.735195 & & 3.939105 & \\
\hline $\mathbf{8}$ & 1.126286 & & 1.28556 & \\
\hline $\mathbf{9}$ & 7.412 & & 5.977355 & \\
\hline $\mathbf{1 0}$ & 1.126286 & & 1.10388 & \\
\hline $\mathbf{1 1}$ & 1.126286 & & 1.10388 & \\
\hline $\mathbf{1 2}$ & 3.745908 & & 4.06575 & \\
\hline
\end{tabular}

For $A U C_{0-t}$ parameter

Table (7-a): Eigen-Values for the Linear and Logarithmic Scales for $A U C_{0-t}$

\begin{tabular}{|c|c|c|c|c|c|c|c|c|}
\hline & \multicolumn{3}{|c|}{ Linear Scale } & Threshol & \multicolumn{3}{|c|}{ Logarithmic Scale } & Threshol \\
\hline & $\begin{array}{l}\text { Eigen } \\
\text { values }\end{array}$ & Proportion & Cumulative & & $\begin{array}{l}\text { Eigen } \\
\text { values }\end{array}$ & Proportion & Cumulative & \\
\hline 1 & 2.4308 & 0.810 & 0.810 & 10.0015 & 2.5881 & 0.863 & 0.863 & 10.37676 \\
\hline 2 & 0.4532 & 0.151 & 0.961 & & 0.3034 & 0.101 & 0.964 & \\
\hline 3 & 0.1160 & 0.039 & 1 & & 0.1085 & 0.036 & 1 & \\
\hline
\end{tabular}

Table (7-b): Threshold Value and the Squared Distance on Linear and Logarithmic Scale

\begin{tabular}{|c|c|c|c|c|}
\hline \multirow{2}{*}{ Subjects } & \multicolumn{2}{|c|}{ Linear scale } & \multicolumn{2}{c|}{ Logarithmic Scale } \\
\cline { 2 - 5 } & $\begin{array}{l}\text { Squared } \\
\text { distance }\end{array}$ & $\boldsymbol{m}$ & $\begin{array}{l}\text { Squared } \\
\text { distance }\end{array}$ & $\boldsymbol{m}$ \\
\hline $\mathbf{1}$ & 0.30391 & $\mathbf{1 0 . 0 0 1 5}$ & 0.256611 & $\mathbf{1 0 . 3 7 6 7 6 6}$ \\
\hline $\mathbf{2}$ & 4.858578 & & 6.737077 & \\
\hline $\mathbf{3}$ & 8.096736 & & 6.476307 & \\
\hline $\mathbf{4}$ & 1.124955 & & 1.157936 & \\
\hline $\mathbf{5}$ & 1.273431 & & 1.094553 & \\
\hline $\mathbf{6}$ & 0.1008 & & 0.126238 & \\
\hline $\mathbf{7}$ & 5.881876 & & 8.683825 & \\
\hline
\end{tabular}




\begin{tabular}{|c|c|l|l|l|}
\hline $\mathbf{8}$ & 0.398347 & & 0.168179 & \\
\hline $\mathbf{9}$ & 0.035312 & & 0.024426 & \\
\hline $\mathbf{1 0}$ & 7.350513 & & 5.327044 & \\
\hline $\mathbf{1 1}$ & 0.435668 & & 0.417511 & \\
\hline $\mathbf{1 2}$ & 3.139874 & & 2.530292 & \\
\hline
\end{tabular}

For $A U C_{\left(0_{-} \infty\right)}$ parameter

Table (8-a): Eigen-Values for the Linear and Logarithmic Scales for $A U C_{(0-} \infty$,

\begin{tabular}{|c|c|c|c|c|c|c|c|c|}
\hline & \multicolumn{3}{|c|}{ Linear Scale } & $m$ & \multicolumn{3}{|c|}{ Logarithmic Scale } & $m$ \\
\hline & $\begin{array}{l}\text { Eigen } \\
\text { values }\end{array}$ & Proportion & Cumulative & & $\begin{array}{l}\text { Eigen } \\
\text { values }\end{array}$ & Proportion & Cumulative & \\
\hline 1 & 2.5341 & 0.845 & 0.845 & 10.24434 & 2.6448 & 0.882 & 0.882 & 10.5203 \\
\hline 2 & 0.3551 & 0.118 & 0.963 & & 0.2531 & 0.084 & 0.966 & \\
\hline 3 & 0.1109 & 0.037 & 1 & & 0.1021 & 0.034 & 1 & \\
\hline
\end{tabular}

Table (8-b): Threshold Value and the Squared Distance on Linear and Logarithmic Scales

\begin{tabular}{|c|c|c|c|c|}
\hline \multirow{2}{*}{ subjects } & \multicolumn{2}{|c|}{ Linear scale } & \multicolumn{2}{c|}{ Logarithmic Scale } \\
\cline { 2 - 5 } & $\begin{array}{l}\text { Squared } \\
\text { distance }\end{array}$ & $\boldsymbol{m}$ & $\begin{array}{l}\text { Squared } \\
\text { distance }\end{array}$ & $\boldsymbol{m}$ \\
\hline $\mathbf{1}$ & 0.330807 & $\mathbf{1 0 . 2 4 4 3 3 9}$ & 0.243947 & $\mathbf{1 0 . 5 2 0 3}$ \\
\hline $\mathbf{2}$ & 4.507126 & & 6.251101 & \\
\hline $\mathbf{3}$ & 9.3847 & & 7.246678 & \\
\hline $\mathbf{4}$ & 1.047287 & & 1.113829 & \\
\hline $\mathbf{5}$ & 1.339328 & & 1.098742 & \\
\hline $\mathbf{6}$ & 0.13412 & & 0.141676 & \\
\hline $\mathbf{7}$ & 5.74696 & & 8.605466 & \\
\hline $\mathbf{8}$ & 0.468563 & & 0.202925 & \\
\hline $\mathbf{9}$ & 0.126915 & & 0.033461 & \\
\hline $\mathbf{1 0}$ & 6.504686 & & 5.19097 & \\
\hline
\end{tabular}




\begin{tabular}{|l|l|l|l|l|}
\hline $\mathbf{1 1}$ & 0.888945 & & 0.77215 & \\
\hline $\mathbf{1 2}$ & 2.520565 & & 2.099056 & \\
\hline
\end{tabular}

\section{Cook's Distance for 2x2 Crossover Design}

Table 9: Cook's distance Value for $\ln C_{\max }, \ln T_{\max }, \ln A U C_{0-t}$ and $\ln A U C_{(0-\infty)}$,

\begin{tabular}{|c|c|c|c|c|c|c|c|c|c|}
\hline Drug & $\begin{array}{l}\text { OB } \\
\mathbf{S}\end{array}$ & $\begin{array}{l}\text { COOK } \\
\text { 'S C }{ }_{\text {max }}\end{array}$ & $m$ & $\begin{array}{l}\text { COOK } \\
\text { 'S T } \mathbf{T}_{\max }\end{array}$ & $m$ & $\begin{array}{c}\text { COOK'S } \\
A U C_{0-t}\end{array}$ & $m$ & $\begin{array}{c}\mathrm{COOK}^{\prime} \\
\mathrm{S} \\
\boldsymbol{A U} \boldsymbol{C}_{(0-} \\
\infty,\end{array}$ & $m$ \\
\hline \multirow{19}{*}{$\mathbf{T}$} & 1 & 0.0068 & 0.0677 & 0.1011 & 0.0725 & 0.0500 & 0.0704 & 0.0356 & 0.0675 \\
\hline & 2 & 0.0206 & & 0.0914 & & 0.0368 & & 0.0237 & \\
\hline & 3 & 0.0273 & & 0.0195 & & 0.0100 & & 0.0000 & \\
\hline & 4 & 0.0018 & & 0.0015 & & 0.0004 & & 0.0001 & \\
\hline & 5 & 0.0219 & & 0.0000 & & 0.0205 & & 0.0019 & \\
\hline & 6 & 0.0569 & & 0.0287 & & 0.0082 & & 0.0001 & \\
\hline & 7 & 0.0051 & & 0.0536 & & 0.0251 & & 0.0049 & \\
\hline & 8 & 0.0026 & & 0.0000 & & 0.0063 & & 0.0043 & \\
\hline & 9 & 0.0016 & & 0.0087 & & 0.0088 & & 0.0124 & \\
\hline & 10 & 0.0202 & & 0.0033 & & 0.0435 & & 0.0111 & \\
\hline & 11 & 0.0000 & & 0.0036 & & 0.0032 & & 0.0000 & \\
\hline & 12 & 0.0398 & & 0.0004 & & 0.0008 & & 0.0023 & \\
\hline & 13 & 0.0444 & & 0.0010 & & 0.0177 & & 0.0160 & \\
\hline & 14 & 0.0006 & & 0.0297 & & 0.0014 & & 0.0006 & \\
\hline & 15 & 0.0114 & & 0.0221 & & 0.0009 & & 0.2023 & \\
\hline & 16 & 0.0097 & & 0.0021 & & 0.0053 & & 0.0034 & \\
\hline & 17 & 0.0142 & & 0.0038 & & 0.0414 & & 0.0648 & \\
\hline & 18 & 0.0226 & & 0.0010 & & 0.1125 & & 0.0377 & \\
\hline & 19 & 0.0014 & & 0.0000 & & 0.0023 & & 0.0006 & \\
\hline
\end{tabular}




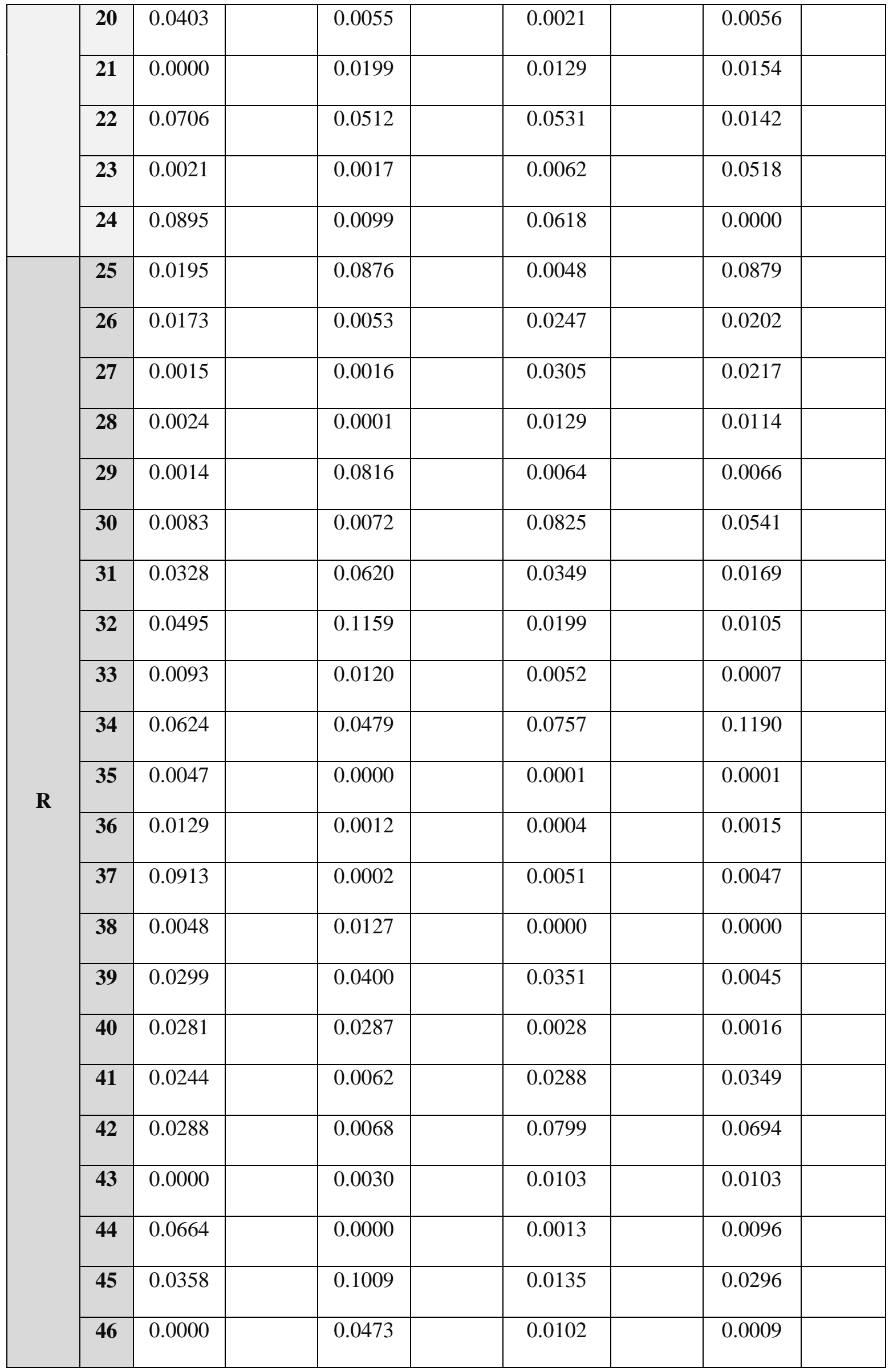




\begin{tabular}{|l|l|l|l|l|l|l|l|l|l|}
\hline & $\mathbf{4 7}$ & 0.0372 & & 0.0297 & & 0.0826 & & 0.0535 & \\
\cline { 2 - 9 } & $\mathbf{4 8}$ & 0.0035 & & 0.0016 & & 0.0276 & & 0.0017 & \\
\hline
\end{tabular}

Cook's Distance for 3x3 Crossover Design

Table 10: Cook's distance Values for $C_{\max }, T_{\max }, A U C_{0-t}$ and $A U C_{(0-} \infty$,

\begin{tabular}{|c|c|c|c|c|c|c|c|c|c|}
\hline Drug & OBS & $\begin{array}{c}\text { COOK'S } \\
\text { C }_{\max }\end{array}$ & $m$ & $\mathrm{COOK}^{\prime} \mathrm{S} \mathrm{T}_{\max }$ & $m$ & $\begin{array}{c}\text { COOK'S } \\
\text { AUC }_{0-\mathrm{t}}\end{array}$ & $m$ & $\begin{array}{c}\text { COOK'S } \\
\text { AUC }_{\text {inf }}\end{array}$ & $m$ \\
\hline \multirow{12}{*}{ T1 } & 1 & 0.030431 & 0.0802 & 0.000002 & 0.0889 & 0.031649 & 0.0779 & 0.000081 & 0.0966 \\
\hline & 2 & 0.005612 & & 0.021422 & & 0.019380 & & 0.020300 & \\
\hline & 3 & 0.038988 & & 0.020685 & & 0.112348 & & 0.044706 & \\
\hline & 4 & 0.116609 & & 0.028495 & & 0.043810 & & 0.024818 & \\
\hline & 5 & 0.006914 & & 0.012633 & & 0.000812 & & 0.000108 & \\
\hline & 6 & 0.004686 & & 0.060982 & & 0.057662 & & 0.016659 & \\
\hline & 7 & 0.044037 & & 0.018569 & & 0.111962 & & 0.095650 & \\
\hline & 8 & 0.020028 & & 0.002222 & & 0.007089 & & 0.021076 & \\
\hline & 9 & 0.008404 & & 0.052330 & & 0.006920 & & 0.000394 & \\
\hline & 10 & 0.078773 & & 0.007516 & & 0.042691 & & 0.019433 & \\
\hline & 11 & 0.003062 & & 0.007880 & & 0.018826 & & 0.019606 & \\
\hline & 12 & 0.065642 & & 0.055915 & & 0.000194 & & 0.003490 & \\
\hline \multirow{9}{*}{$\mathrm{T} 2$} & 13 & 0.065695 & & 0.006028 & & 0.000331 & & 0.002584 & \\
\hline & 14 & 0.000050 & & 0.116658 & & 0.000016 & & 0.000000 & \\
\hline & 15 & 0.020431 & & 0.001736 & & 0.072012 & & 0.026036 & \\
\hline & 16 & 0.004410 & & 0.004891 & & 0.007800 & & 0.000024 & \\
\hline & 17 & 0.013448 & & 0.037754 & & 0.023566 & & 0.020268 & \\
\hline & 18 & 0.000226 & & 0.002034 & & 0.000312 & & 0.000001 & \\
\hline & 19 & 0.067868 & & 0.015223 & & 0.046745 & & 0.021412 & \\
\hline & 20 & 0.018985 & & 0.039670 & & 0.012072 & & 0.003240 & \\
\hline & 21 & 0.005514 & & 0.086818 & & 0.002038 & & 0.007522 & \\
\hline
\end{tabular}




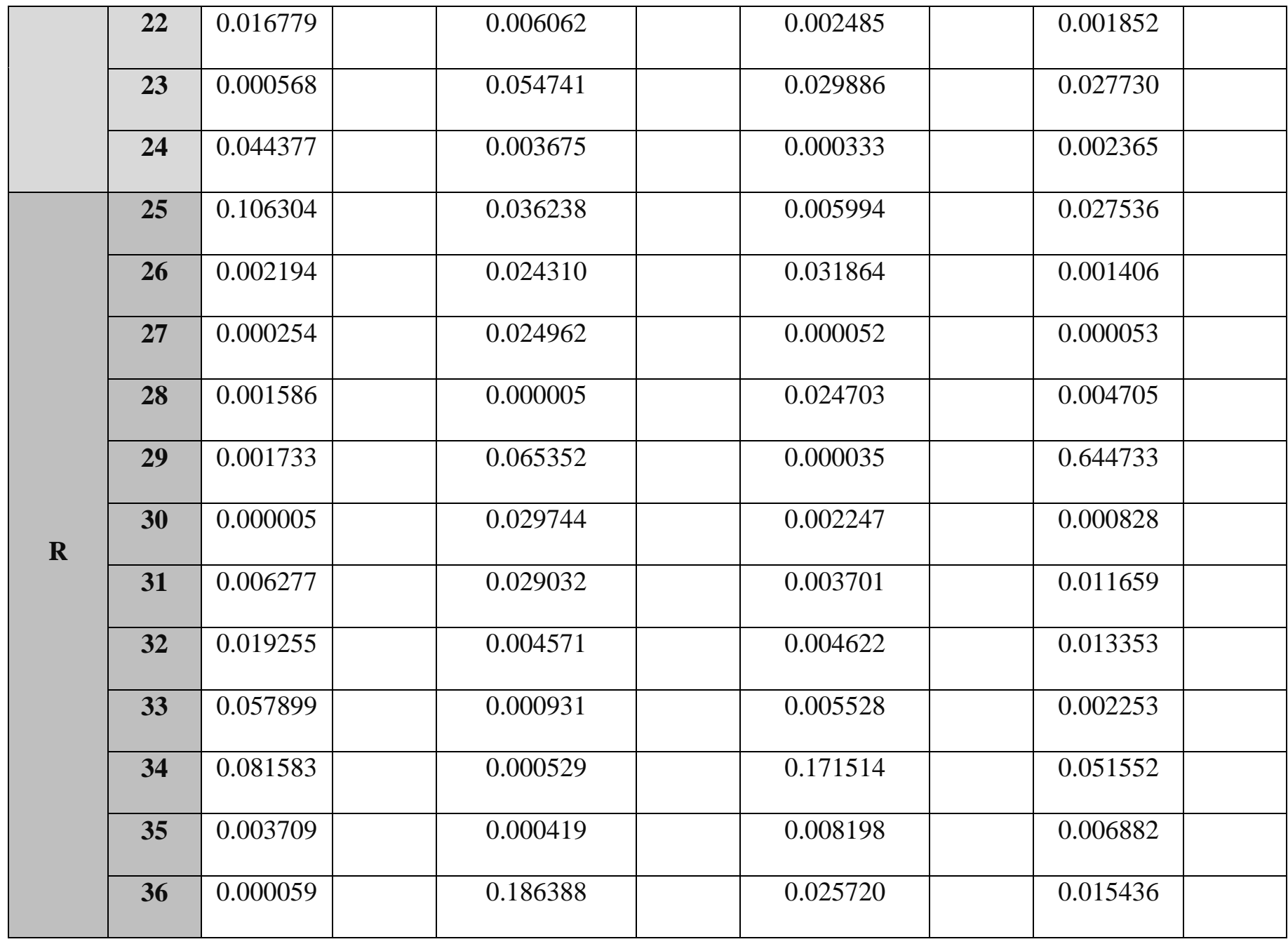


APPENDIX (B)

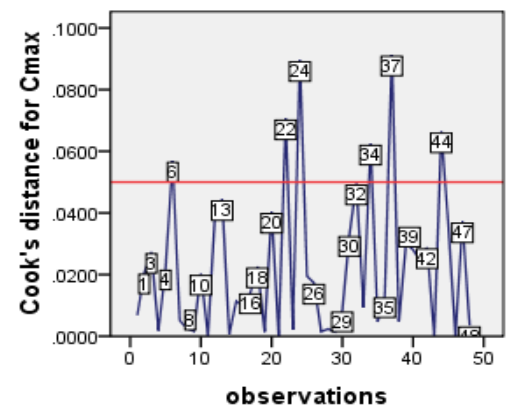

Figure1: Fit Outliers Plot for $\mathrm{C}_{\max }$

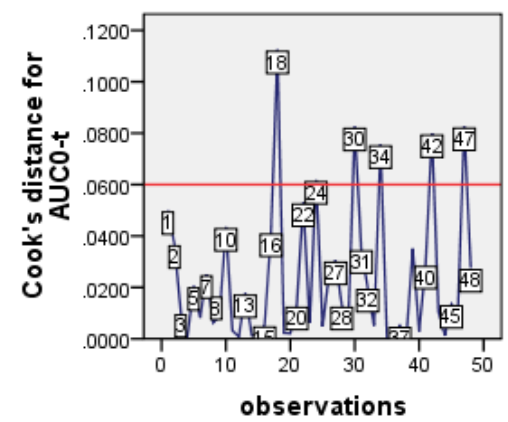

Figure 3: Fit Outliers Plot for $\mathrm{AUC}_{(0-\mathrm{t})}$

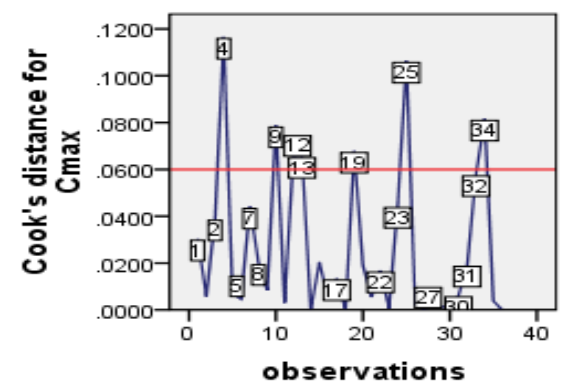

Figure 5: Fit Outliers Plot for $\mathrm{C}_{\max }$

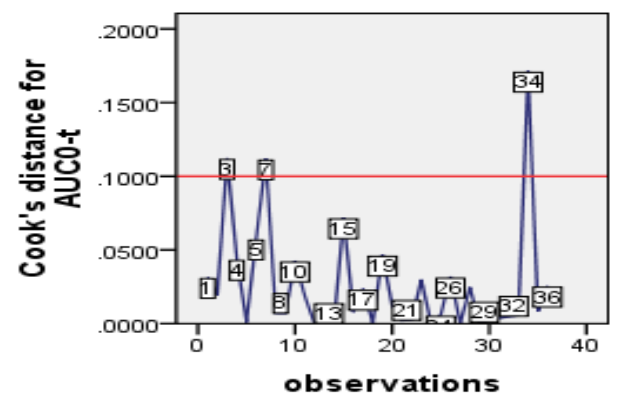

Figure 7: Fit Outliers Plot for AUC(0-t)

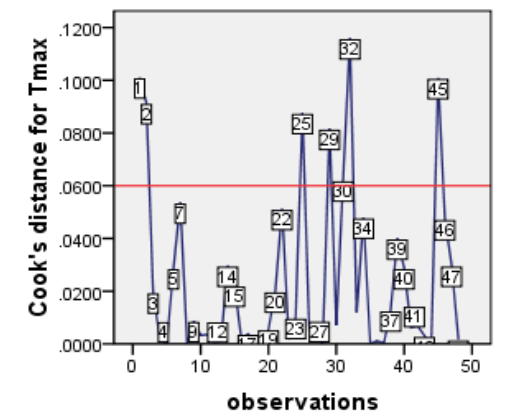

Figure2: Fit Outliers Plot for $\mathrm{T}_{\max }$

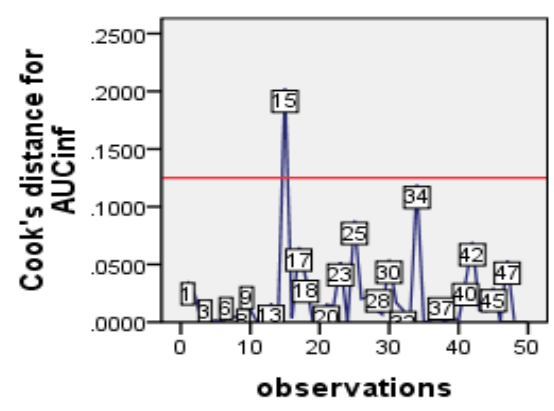

Figure 4: Fit Outliers Plot for $A U C_{\left(0_{-}\right.} \infty$ )

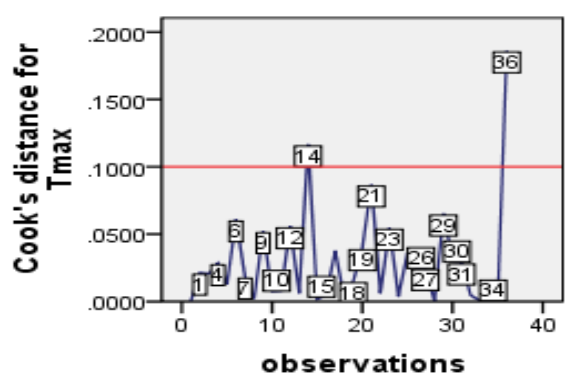

Figure 6: Fit Outliers Plot for $\mathrm{T}_{\max }$

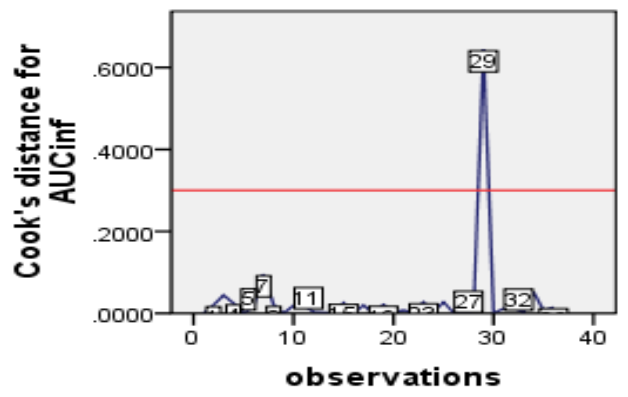

Figure 8: Fit Outliers Plot for $A U C_{\left(0_{-}\right.} \infty$ ) 